\title{
Long-Term Overexpression of Heme Oxygenase 1 Promotes Tau Aggregation in Mouse Brain by Inducing Tau Phosphorylation
}

\author{
Yang Hui ${ }^{\mathrm{a}}$, Dayong Wang ${ }^{\mathrm{a}}$, Wenjing Li ${ }^{\mathrm{a}, \mathrm{b}}$, Lina Zhang ${ }^{\mathrm{a}, \mathrm{c}}$, Jianfeng Jin ${ }^{\mathrm{a}}$, Ning Ma ${ }^{\mathrm{a}}$, Lingyun Zhou ${ }^{\mathrm{a}}$, \\ Osamu Nakajima ${ }^{\mathrm{d}}$, Weiming $\mathrm{Zhao}^{\mathrm{a}, *}$ and $\mathrm{Xu} \mathrm{Gao}^{\mathrm{a}, *}$ \\ ${ }^{a}$ Department of Biochemistry and Molecular Biology, Harbin Medical University, Harbin, China \\ b ADICON Clinical Laboratories, Hangzhou, China \\ ${ }^{\mathrm{c} C l i n i c a l}$ Laboratory Department, Daqing Oilfield General Hospital, Daqing, China \\ ${ }^{\mathrm{d}}$ Research Laboratory for Molecular Genetics, Yamagata University, Yamagata, Japan
}

Handling Associate Editor: Wolff Kirsch

Accepted 6 April 2011

\begin{abstract}
Intracellular tau aggregates composed of neurofibrillary tangles (NFTs) are a defining feature of Alzheimer's disease (AD). Increased expression of heme oxygenase-1 (HO-1) is a common phenomenon in AD. Interestingly, the spatial distribution of HO-1 expression is essentially identical to that of pathological accumulation of tau in AD. In this study, we developed a new transgenic mouse overexpressing HO-1, called CAG-HO-1 Tg mice, to explore the relationship between HO-1 and tau aggregation. In this model, we found that long-term overexpression of HO-1 significantly promoted tau aggregation in brain, by analyzing changes in morphology and insoluble tau expression levels. Moreover, our research provides the first in vivo evidence that HO-1 can enhance iron loading and tau (Ser199/202/396) phosphorylation in brains of transgenic mice. Cellular evidence indicates that HO-1 can induce the phosphorylation of tau through iron accumulation in Neuro2a cells stably transfected with HO-1. Our data suggest that long-term overexpression of HO-1 can promote tau aggregation. This mechanism involves excessive iron production mediated by HO-1 overexpression, which induces tau phosphorylation. Our results provide a potential pathway for the pathogenesis of tauopathies, which remains largely unknown.
\end{abstract}

Keywords: Alzheimer's disease, heme oxygenase 1, iron, tau, transgenic mice

\section{INTRODUCTION}

Alzheimer's disease (AD) is an age-related progressive neurodegenerative disorder and the leading cause of dementia [1]. AD is predominantly characterized by the presence of amyloid- $\beta(A \beta)$ deposition, intracellu-

${ }^{*}$ Correspondence to: Xu Gao, Tel.: +86 451 86671684; Fax: +86 4518708 6131; E-mail: gaoxu6712@yahoo.com.cn and Weiming Zhao, Tel.: 86451 86624142; E-mail: zhaowm@ems.hrbmu.edu.cn. lar neurofibrillary tangles (NFT), progressive loss of neurons, inflammatory responses, oxidative stress, and mitochondrial dysfunction. The NFTs observed in AD neurons consist of hyperphosphorylated, insoluble tau protein, resulting in tau aggregation [2]. Recent findings provide further support for the central role of tau in the pathogenesis of $\mathrm{AD}$, demonstrating that tau phosphorylation and aggregation may be the final common pathway in this multifactorial disease. As a result, tau has become a diagnostic and therapeutic target for the 
disease [3]. By binding microtubules and promoting their polymerization, tau plays a crucial role in maintaining the physiological function of healthy neurons. Both direct toxic effects of aggregated tau and/or loss of axonal transport, due to transition of soluble tau into hyperphosphorylated and aggregated forms that are no longer capable of supporting axonal transport, have been proposed to contribute to AD [4].

There is evidence indicating that heme oxygenase-1 (HO-1) is involved in AD. HO-1 is a $32 \mathrm{kDa}$ protein that plays a key role in decomposing heme to biliverdin, freeing ferrous iron and carbon monoxide. Biliverdin reductase further degrades biliverdin to the bile pigment bilirubin [5]. HO-1 expression in normal, unstressed mammalian (rodent) brain is sparse and confined to scattered neuroglia, small populations of neurons in the cerebellum (Purkinje cells), thalamus, hypothalamus, brain stem, hippocampal dentate gyrus, and cerebral cortex [6].

HO- 1 is a stress protein induced in response to a variety of oxidative stressors. Oxidative stress, engendered by pro-inflammatory cytokines, amyloid burden, accumulation of tau in neurofibrillary tangles, and infidelity of electron transport in senescent mitochondria, may contribute to up-regulation of neural HO-1 in AD $[7,8]$.

Using immunolabeling techniques, significant overexpression of HO-1 in brains derived from human with neuropathologically-proven AD relative to agematched controls with no history of neurological illness was found by Schipper et al. [9]. Similarly, western blots of protein extracts prepared from the temporal cortex and hippocampus from AD patients brains exhibited robust $\mathrm{HO}-1$ expression compared to neurohistologically normal controls matched for age and post-mortem interval [9]. In fact, upregulation of HO-1 appears to be an early occurrence in AD brains and correlates with decreased cognitive function [10].

$\mathrm{HO}-1$ is upregulated in $\mathrm{AD}$ brain tissue and is associated with neurofibrillary tangles and senile plaque neuritis [11]. HO-1 immunoreactivity is greatly enhanced in neurons and astrocytes of the hippocampus and cerebral cortex of subjects with $\mathrm{AD}$ and co-localizes with senile plaques, NFTs and corpora amylacea [12]. The results of an mild cognitive impairment (MCI) study strongly suggest that glial HO-1 induction is a relatively early event in the pathogenesis of sporadic AD [10].

Accordingly, we speculate that there is a correlation between HO-1 overexpression and AD. However, the function of $\mathrm{HO}-1$ in the pathogenesis of $\mathrm{AD}$ remains unclear. Most studies on the role of HO-1 in AD were conducted in vitro. Because $\mathrm{AD}$ is a degenerative disease resulting from long-term effects, experiments in cultured cells might not faithfully recapitulate this process. As a result, we were interested in the long-term effects of HO-1 in vivo. For this reason, we created a $\mathrm{HO}-1$ overexpressing transgenic mouse model to study its function in the pathogenesis of $\mathrm{AD}$ and the mechanisms involved in this process.

\section{METHOD}

\section{Generation and selection of transgenic mice}

Transgenic mice were generated by the standard pronuclear injection technique using C57BL/6 mice [13]. For construction of the transgene, mouse HO-1 cDNA was cloned into a pCAGG plasmid. Expression of mouse HO-1 cDNA was driven by the chicken $\beta$-actin promoter linked to a human cytomegalovirus immediate-early enhancer, followed by first exon and intron of chicken $\beta$-actin. Mouse HO- 1 transcript, with its own stop codon and poly(A) signal, was followed by a rabbit $\beta$-globin poly(A) sequence. The mRNA transcript of the transgene therefore consisted of part of the first exon of chicken $\beta$-actin, which is transcribed but not translated, followed by mouse HO-1 cDNA.

All of the animals were genotyped by PCR amplification of DNA extracted from the tails of mice to assess the presence of the mouse HO-1 transgene. The region from the exon of the pCAGG vector to exon 1 of HO-1 was amplified with the following primers: $5^{\prime}$ GCC TTC TTC TTT TTC CTA CAG CTC $3^{\prime}$ and $5^{\prime}$ GGC ATG TCG GGC TGT GGAC 3'.

Experiments were performed in compliance with protocols approved by the National Institutes of Health Guide for the Care and Use of Laboratory Animals. Throughout the study period, animals were housed in a controlled environment (temperature $22^{\circ} \mathrm{C}$, humidity $45-55 \%, 12 \mathrm{~h}$ light $/ 12 \mathrm{~h}$ dark schedule), and efforts were made to minimize discomfort and the number of animals used.

\section{Transgene expression analysis}

Transgene mRNA expression was analyzed by reverse transcription-coupled quantitative real-time PCR (qRT-PCR). Total RNA from the hippocampus of $\mathrm{Tg}$ and wt mice was isolated and retro-transcribed into cDNA using a Reverse Transcription System Kit (Promega), according to the manufacturer's protocol. For reverse transcription (RT), the reaction was incubated at $25^{\circ} \mathrm{C}$ for $5 \mathrm{~min}$, followed by a $15 \mathrm{~min}$ 
Table 1

Antibody characteristics

\begin{tabular}{lllr}
\hline Protein & Antibody & Manufacturer & Band Size \\
\hline Tau & Ab75624 polyclonal & Abcam & $55 \mathrm{KD}$ \\
Tau(Tau-5) & MAB361 monoclonal & Millipore & $45-68 \mathrm{KD}$ \\
P-Tau(Ser199/ser202) & Ab4864 polyclonal & Abcam & $62 \mathrm{KD}$ \\
P-Tau(Ser396) & Ab30663 polyclonal & Abcam & $48 \mathrm{KD}$ \\
HO-1(H-105) & sc-10789 Polyclonal & Santa Cruz & $32 \mathrm{KD}$ \\
GAPDH (14C10) & \#2118 monoclonal & Cell Signalling Techology & $37 \mathrm{KD}$ \\
\hline
\end{tabular}

incubation at $70^{\circ} \mathrm{C}$ and a subsequent $1 \mathrm{~h}$ incubation at $42^{\circ} \mathrm{C}$. A total of $30 \mathrm{ng}$ of cDNA, $200 \mathrm{nM}$ of both sense and antisense primers and SYBR Green Supermix (Takala) at a final volume of $25 \mu l$ was used for PCR. Reactions were carried out in an ABI PRISM 7500 RT-PCR machine using optimized primers. The primer sequences were as follows:

- HO-1 sense, 5'-GAAGAACTTTCAGAAGGG TCAG-3';

- HO-1 antisense, 5'-TCGTCGGAGACGCTTTA CATAG-3';

- GAPDH sense, 5'-GTTGTCTCCTGCGACTT CA-3';

- GAPDH antisense, 5'-GGTGGTCCAGGGTTT CTTA- $3^{\prime}$.

As an internal control, GAPDH primers were used for RNA template normalization. Fluorescent signals were normalized to an internal reference $(\Delta R \mathrm{n})$, and the threshold cycle $(C \mathrm{t})$ was set within the exponential phase of the PCR. The relative gene expression was calculated by comparing cycle times for each target PCR. The target PCR $C t$ values were normalized by subtracting the GAPDH $C t$ value, which gives the $\Delta C \mathrm{t}$ value. From this value, the relative expression levels between treatments can be calculated using the following equation: relative gene expression $=2^{-\Delta(\Delta \mathrm{Ct})}$.

\section{Immunohistochemistry}

Mice were weighed, overdosed with pentobarbital ( $200 \mathrm{mg} / \mathrm{kg}$ ) and perfused with $25 \mathrm{ml}$ of $0.9 \%$ normal saline solution. Brains were collected from the animals immediately following perfusion and immersion fixed in $4 \%$ paraformaldehyde for $24 \mathrm{~h}$.

Coronal sections were stained using an immunohistochemistry (IHC) procedure. Tissue was permeabilized with PBS-T for $20 \mathrm{~min}$ and incubated in $0.3 \%$ hydrogen peroxide for $20 \mathrm{~min}$ to quench endogenous peroxidases. After washing, tissue was blocked with 5\% normal goat serum (Invitrogen Canada,
Toronto, ON) for $30 \mathrm{~min}$ and incubated overnight at $4{ }^{\circ} \mathrm{C}$ with the tau antibody in Table 1 . The following day, sections were washed and incubated with a biotin-binding secondary antibody (goat-anti-rabbit $\mathrm{IgG}, 1: 100)$ for $20 \mathrm{~min}$. Sections were washed, and staining was developed with $0.05 \%$ DAB (SigmaAldrich Canada, Oakville, ON) and $0.03 \% \mathrm{H}_{2} \mathrm{O}_{2}$. After washing, sections were counterstained with hematoxylin, dehydrated in ascending ethanol concentrations, cleared with xylene, and coverslipped.

Stained sections were imaged using an Olympus bx51 microscope. Digital images were acquired using a Chemidoc-it hr410 imaging system (UVP, CA, USA).

\section{Transmission electron microscopy}

To determine the ultrastructural features of nerve cells in mouse brains, transmission electron microscopy (TEM) was performed in CAG-HO-1-L Tg mice and WT littermates at 14 months of age $(n=3)$. These mice were deeply anesthetized with approximately $50 \mathrm{mg} / \mathrm{kg}$ of sodium pentobarbital (i.p.) and sacrificed by decapitation. The cerebral cortex was removed and fixed in $3 \%$ glutaraldehyde for $2 \mathrm{~h}$. The tissues were post-fixed in $1 \%$ osmium tetroxide for $60 \mathrm{~min}$ at $4{ }^{\circ} \mathrm{C}$. After dehydration with graded acetone, the blocks were embedded in Epon-812 and polymerized at $60^{\circ} \mathrm{C}$ for $72 \mathrm{~h}$. Thin sections were cut and mounted on 200 mesh copper grids, stained with uranyl acetate and lead citrate and examined with a HITACHI electron microscope (H-7650).

Isolation of insoluble tau from mouse hippocampus and cortex

The tissue extracts are always a MIXTURE of hippocampus and cortex. Tissue was homogenized in $300 \mu \mathrm{l}$ buffer A [containing $20 \mathrm{mM}$ Tris- $\mathrm{HCl}, \mathrm{pH} 7.5$, $150 \mathrm{mM} \mathrm{NaCl}, 1 \mathrm{mM}$ EDTA, $1 \mathrm{mM} \mathrm{NaVO} 4,50 \mathrm{mM}$ $\mathrm{NaF}$ with protease inhibitors (Roche Applied Science)] on ice for $30 \mathrm{~min}$ and centrifuged at $1000 \times g$ for $15 \mathrm{~min}$ 
at $4{ }^{\circ} \mathrm{C}$. One percent Triton X-100 was added to supernatants, and samples were separated into soluble and insoluble fractions by centrifugation at $15000 \times g$ for $20 \mathrm{~min}$. The supernatant, containing solution protein, was stored at $-80^{\circ} \mathrm{C}$ and used for western blotting. The precipitate, containing insoluble protein, was dissolved in $1 \% \mathrm{SDS}$, and stored at $-80^{\circ} \mathrm{C}$ for western blotting analysis [14].

\section{Western blotting}

Cells and mouse tissues were lysed in RIPA buffer with protease inhibitors (Roche Applied Science). After incubation at $4{ }^{\circ} \mathrm{C}$ for $30 \mathrm{~min}$, cell and tissues lysates were centrifuged at $12,000 \mathrm{rpm}$ for $20 \mathrm{~min}$ at $4^{\circ} \mathrm{C}$. The supernatant was stored at $-80^{\circ} \mathrm{C}$ for western blotting analysis. Protein concentrations were measured using a BCA kit.

Equal amounts of protein were separated by SDS-polyacrylamide gel electrophoresis (12\% gel) and transferred to nitrocellulose membranes. Membranes were boiled for $10 \mathrm{~min}$ in PBS and blocked with 5\% BSA in TBST $(50 \mathrm{mM}$ Tris- $\mathrm{HCl}, \mathrm{pH} 7.6$, $150 \mathrm{mM} \mathrm{NaCl}, 0.5 \%$ Tween-20) at room temperature for $3 \mathrm{~h}$. Primary antibodies against HO-1 (Santa Cruz, sc10789, $1: 4000$ ), GAPDH (Cell Signaling, 14c10, $1: 2000$ ), tau phosphorylated at S199/S202 (Abcam, ab4864, $1: 1000$ ), tau phosphorylated at S396 (Abcam, ab30663, 1:1000), and tau5 (Miliprore, mab361) in Table 1 were applied overnight at $4{ }^{\circ} \mathrm{C}$. After washing in TBST, the membranes were incubated with suitable secondary antibodies for $2 \mathrm{~h}$ at room temperature, visualized using an enhanced chemiluminescence substrate kit and exposed to film.

\section{Stable transfection of cell lines}

Mouse neuro2a cells (N2A) were grown in Minimum Essential Medium Eagle (MEME, SigmaAldrich, M0643) and 10\% FBS (Gibco) with 5\% $\mathrm{CO}_{2}$ at $37^{\circ} \mathrm{C}$ in an incubator.

Mouse HO-1 cDNA was cloned into a pcDNA3.1 plasmid to create the pcDNA3.1-HO-1 vector.

Cells were seeded one day before transfection with an initial seeding density of $2 \times 105$ cells in six-well plates. For stable transfection assays, the cells were subjected to drug selection $(500 \mu \mathrm{g} / \mathrm{ml}$ G-418 (Amresco)) $48 \mathrm{~h}$ after transfection with lipofectamine 2000 (Invitrogen Corporation, CA, USA) and pcDNA3.1 and pcDNA3.1-HO-1 vectors, according to the manufacturer's instructions. Distinct, antibioticresistant individual colonies appeared after two weeks and were handpicked using a micropipette, dissociated into small clumps of cells and transferred into one well in a 96-well culture dish. Cells were later transferred into a 24-well culture dish. The cells were then expanded in a six-well plate and continuously propagated in the presence of antibiotics. Later we found several stably transfected cell lines using PCR and western blotting. In some experiments, the cells were grown without drug selection.

\section{Iron and DFO treatment}

Iron was supplied to Neuro2a cells as iron citrate (Sigma, F3388), in a supplemental medium, at concentrations of $10 \mu \mathrm{M}, 20 \mu \mathrm{M}, 30 \mu \mathrm{M}, 60 \mu \mathrm{M}$, or $100 \mu \mathrm{M}$. For iron chelating experiments, DFO (deferoxamine mesylate, D533, Sigma) was applied to Neuro2a cells at $100 \mu \mathrm{M}$, in a supplemental medium, four hours after iron treatment. Iron and iron-chelating treatments were performed within $24 \mathrm{~h}$. Cells were then collected for analysis.

\section{Iron assay}

The non-heme iron content of tissue samples was measured as described previously [15]. A standard iron solution was made, which contained $0.1 \mathrm{mg}$ of iron per ml. A 4\% sodium pyrophosphate solution was prepared with iron-free distilled water. Trichloroacetic Acid (TCA) was redistilled, and a 50\% stock solution was made with iron-free distilled water. This stock solution was diluted to a $25 \%$ aqueous solution for use. A $0.4 \%$ solution of a, $\mathrm{a}^{\prime}$-bipyridine (J\&K CHEMICA, 107095 ) was prepared in redistilled $0.005 \mathrm{~N} \mathrm{HCl}$, and a $2 \%$ solution of sodium ascorbate (Amresco, 0561100) was prepared fresh daily in iron-free distilled water.

Two molar acetate buffer ( $\mathrm{pH}$ 4.78) was prepared from reagent-grade sodium acetate and glacial acetic acid made with iron-free water.

Mice were deeply anesthetized and sacrificed by decapitation. Tissue was washed in iron-free water, blotted dry and weighed. Subsequently, tissue was homogenized in $5 \mathrm{ml}$ centrifuge tubes, water was added to bring the volume to $3 \mathrm{ml}$, and the solutions were mixed. Aliquots $(1 \mathrm{ml})$ of the homogenate were placed in $2 \mathrm{ml}$ centrifuge tubes. Then $800 \mu \mathrm{l}$ of an extraction mixture (a $1: 1$ ratio of $25 \%$ TCA and $4 \%$ sodium pyrophosphate solutions) was added to each centrifuge tube. The tubes were placed in a boiling water bath for $15 \mathrm{~min}$. Then the tubes were centrifuged at $2000 \times g$ for $20 \mathrm{~min}$. The supernatant solution was filtered through 

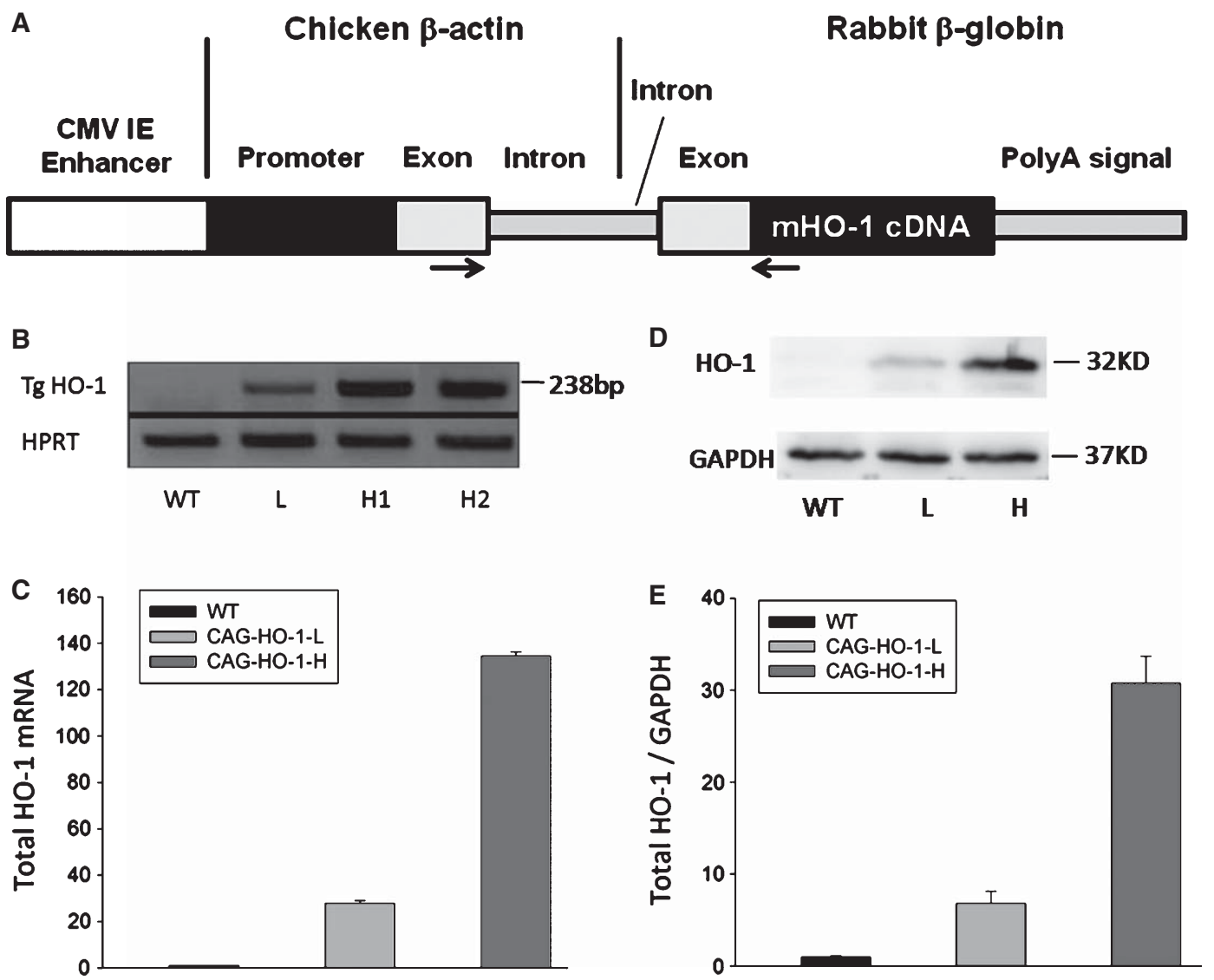

Fig. 1. Generation and characterization of transgenic animals. A) The $C A G-H O$ construct showing the cloning of mHO- 1 cDNA under the transcriptional control of the $C A G$ promoter. The approximate location of primers used in characterizing (screening) $\mathrm{Tg}$ mice is indicated by the arrows. B) Founders were genotyped by PCR analysis with DNA isolated from tail biopsies. To genotype Tg mice, PCR was used to amplify the region from the exon of the pCAGG vector to exon 1 of HO-1. No signal was detected in the samples from WT littermates, while an obvious band with the expected length, corresponding to the transgene, was specifically found in Tg mice. C) Analysis of total HO-1 mRNA expression in brain tissues was performed by qRT-PCR. D) HO-1 protein production in brain lysates was detected by western blotting. E) Graph showing semi-quantitative analyses of western blotting. (H, high expression line; L, low expression line; WT, wild-type.)

a $0.45 \mu \mathrm{m}$ bacterial filter and collected into $5 \mathrm{ml}$ centrifuge tubes. The sediment was resuspended, heated, centrifuged, and filtered as described above. After this second extraction, the filtrates were combined, and the volume was brought to $2 \mathrm{ml}$ with iron-free water.

Three-hundred microliter aliquots of the filtrate, $100 \mu \mathrm{l}$ of sodium ascorbate, $100 \mu \mathrm{l}$ of a, $\mathrm{a}^{\prime}$-bipyridine and $200 \mu \mathrm{l}$ of acetate buffer were added to the unknown samples. The same reagents were added to the blank sample (B1), except the a, $\mathrm{a}^{\prime}$-bipyridine solution was replaced with $100 \mu \mathrm{l}$ of distilled water. A standard was prepared by substituting $100 \mu \mathrm{l}$ of an aqueous iron solution $(5 \mu \mathrm{g} / \mathrm{ml}), 100 \mu \mathrm{l}$ of sodium pyrophosphate and $100 \mu \mathrm{l}$ of trichloroacetic acid solution for the filtrate; the same reagents added to the unknown samples were then added to the standard. A standard blank (B2) was prepared in a similar manner to the standard, except that $100 \mu l$ of distilled water was substituted for the iron solution. A reagent blank (B3) was made using $100 \mu \mathrm{l}$ of distilled water, $100 \mu \mathrm{l}$ of sodium ascorbate and $200 \mu \mathrm{l}$ of acetate buffer. All tubes were mixed and allowed to incubate at room temperature for $30 \mathrm{~min}$. Then the optical density was measured in a spectrophotometer with the wavelength set at $520 \mathrm{~nm}$.

The quantity of iron in each sample was calculated by the following formula:

$$
\frac{\left(O D_{\text {sample }}-O D_{\mathrm{B} 1}\right)-\left(O D_{\mathrm{B} 2}-O D_{\mathrm{B} 3}\right)}{\left(O D_{\text {standard }}-O D_{\mathrm{B} 2}\right)} \times 5 u g \times 20 \times 3
$$




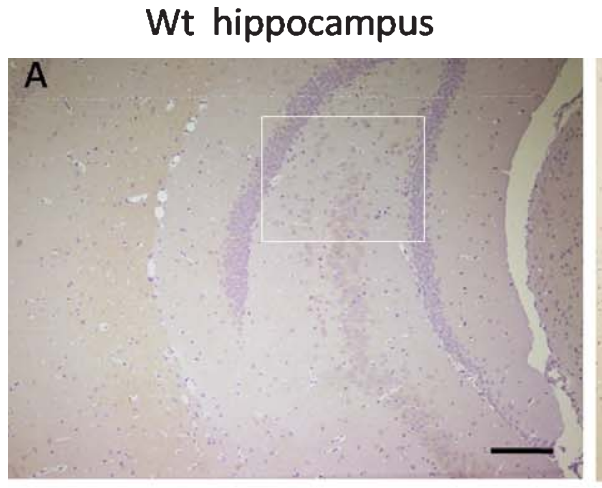

\section{CAG-HO-1-L hippocampus}
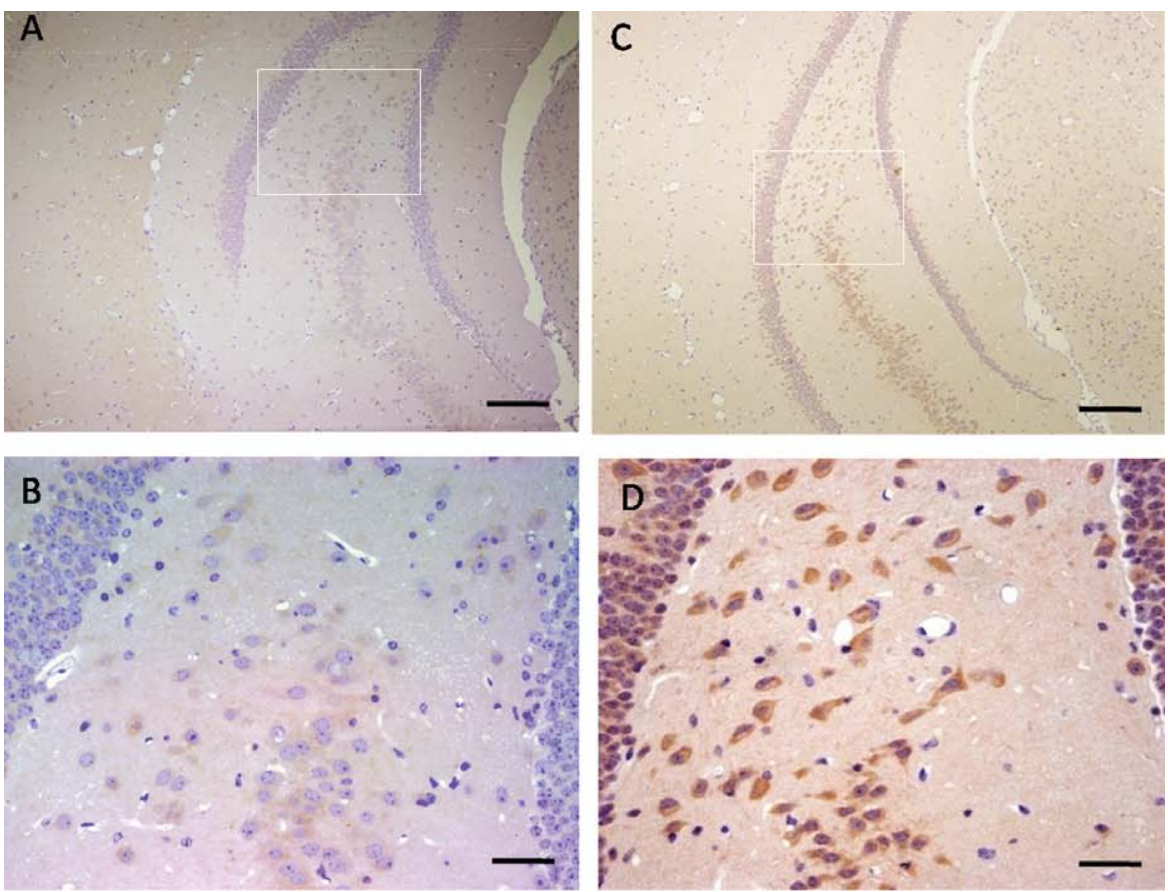

Wt cortex
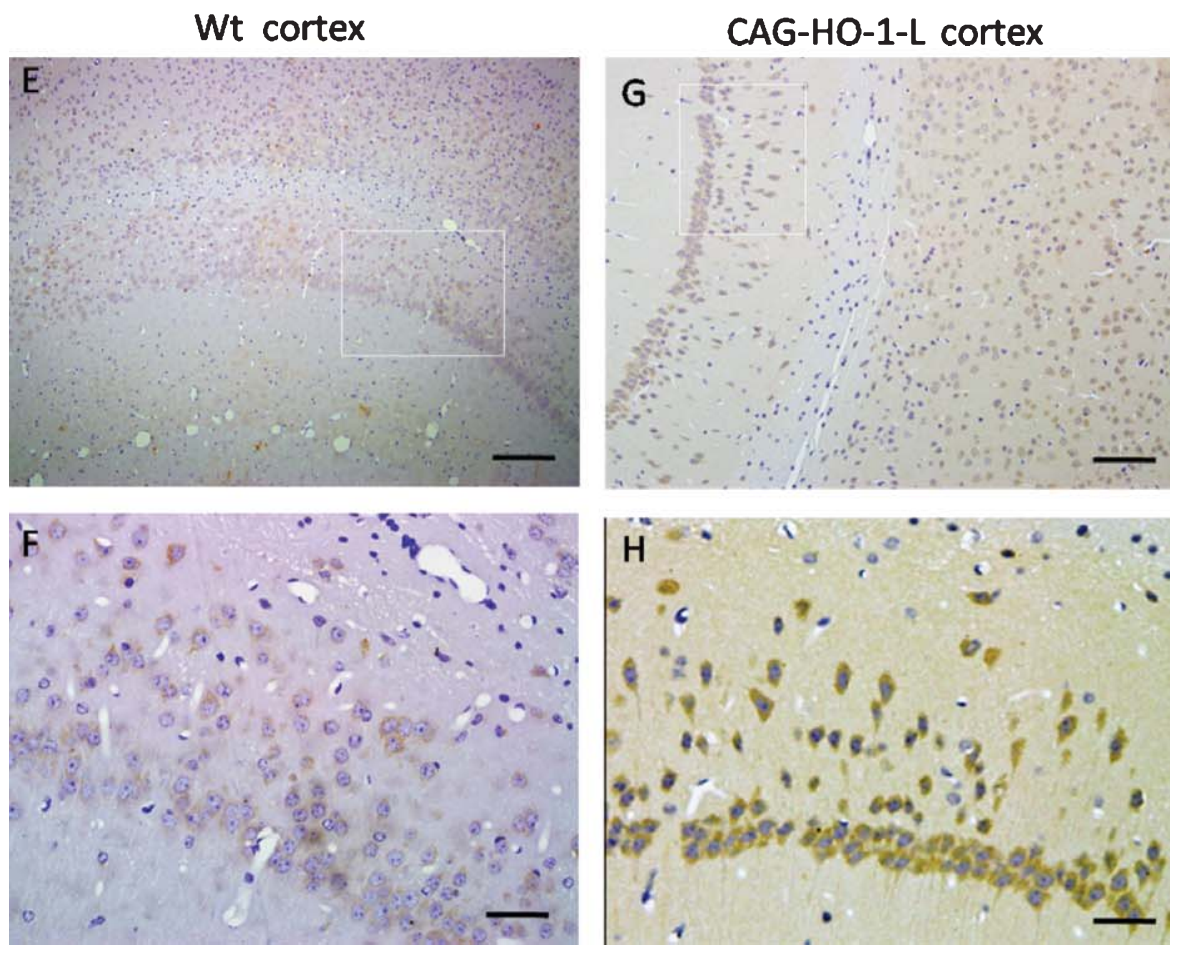

Fig. 2. Immunohistochemical staining of tau in brains of CAG-HO-1 Tg mice. The mice used were the low expression transgenic line and WT littermates at 4 months old. A mouse polyclonal antibody was used to detect total tau immunoreactivity in fixed tissue. A, C) Staining in the hippocampus of WT and CAG-HO-1-L Tg mice, respectively. B, D) Higher magnifications of regions from A and C. E, G) Staining in the cerebral cortex of WT and CAG-HO-1-L Tg mice, respectively. F, H) Higher magnifications of regions from E and G; intraneuronal accumulation of tau is well-established and tau immunoreactivity is shown by the brown staining. Both pyramidal neurons of the hippocampus and cerebral cortex appear intensely stained. Scale bars: A, C, E, G, $500 \mu \mathrm{m}$; B, D, F, H, $5 \mu \mathrm{m}$. 

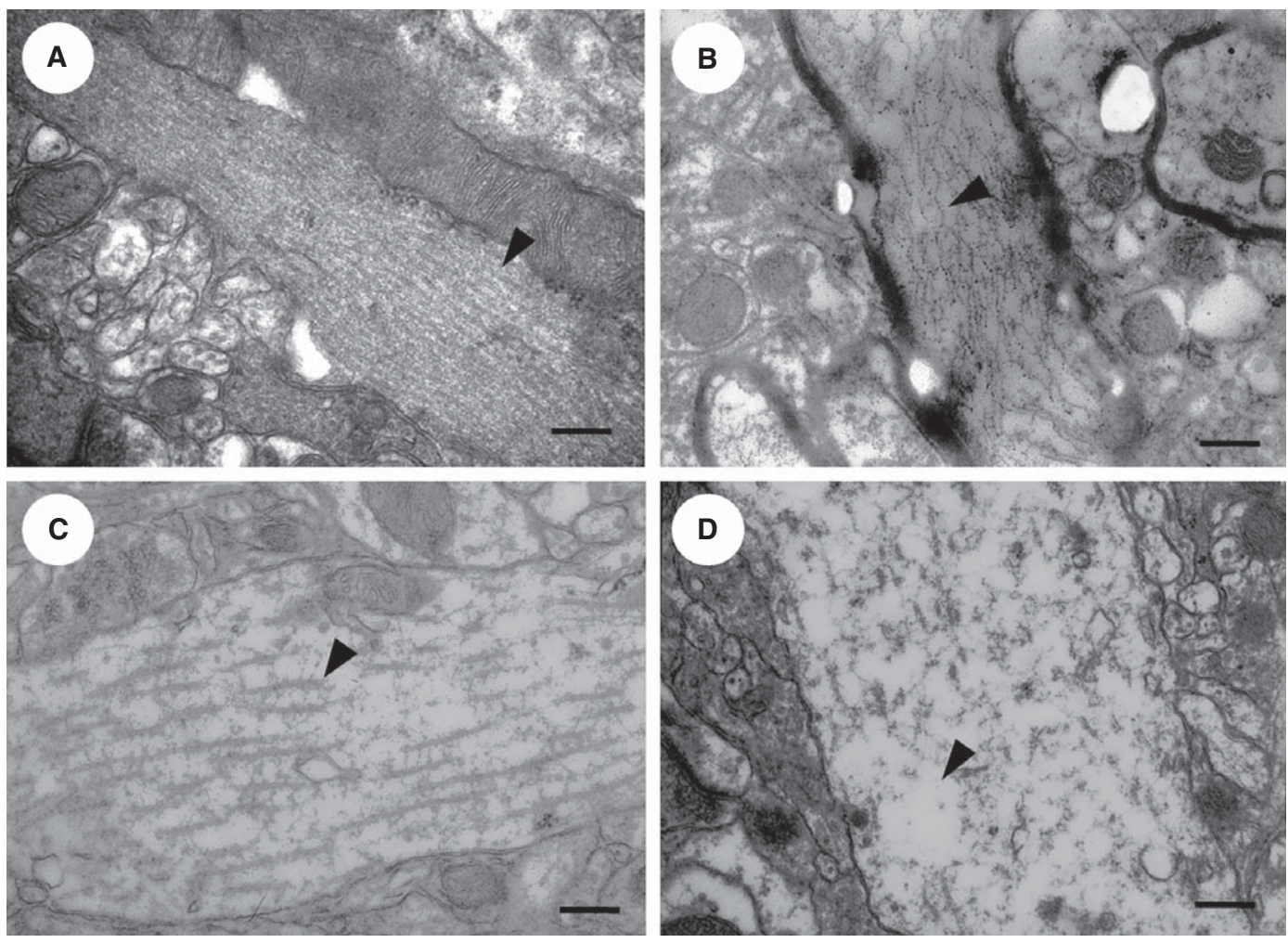

Fig. 3. Ultrastructure of the cerebral cortex of CAG-HO-1 Tg mice. The ultrastructure of microtubules in the cerebral cortex of Tg mice was studied by electron microscopy. A) Normal microtubules lined up in order in WT mice. B) Microtubules were twining and spread loosely in 9-month-old CAG-HO-1-L Tg mice. C) Microtubules were disrupted in 12-month-old CAG-HO-1-L Tg mice. D) Microtubules dissolved completely, and microfilaments structure disappeared thoroughly in 14-month-old CAG-HO-1-L Tg mice. Scale bars: A, B, C, D, 300 nm. Arrow heads refer to the microtubules (normal, loosely spread, disrupted and disolved).

\section{Statistical analysis}

An independent samples $t$-test (SPSS 16.0) was used to calculate significant $(p<0.05)$ differences. Asterisks in the figures represent statistically significant differences. All of the assays were repeated at least three times; all of the histograms show the mean values \pm S.E.M.

\section{Result 1. Generation of CAG-HO-1 transgenic mice and transgene expression}

CAG-HO-1 Tg mice were developed to express mouse HO-1 under the control of the CAG promoter (Fig. 1A). Six founders were obtained, three of which transmitted the transgene in a Mendelian manner. One of the three lines expressed low levels of exogenous HO-1 (CAG-HO-1-L), and two of the three lines expressed high levels of exogenous HO-1 (CAG$\mathrm{HO}-1-\mathrm{H})$. No exogenous HO-1 signals were found in samples from WT mice (Fig. 1B). The total HO-1
mRNA expression (both exogenous and endogenous) was evaluated in mouse brain samples by qRT-PCR. Expression of HO-1 was significantly higher in brain samples from $\mathrm{Tg}$ mice. The expression level of HO-1 in CAG-HO-1-H (H) mice was approximately 5-fold higher than in CAG-HO-1-L (L) mice (Fig. 1C).

As a consequence of transgene expression, the total $\mathrm{HO}-1$ protein production detected in lysates from the brains of Tg animals was significantly increased compared to wide type littermates(WT). HO-1 expression in CAG-HO-1-L (L) mice was about 4-fold greater than WT, whereas expression in CAG-HO-1-H $(\mathrm{H})$ mice was about 25-fold greater than in WT mice (Fig. 1D).

\section{Result 2. Immunohistochemical staining of tau and CAG-HO-1-L Tg mouse brain ultrastructure}

Tau accumulation in the brains of 14-month-old low expression Tg mice (CAG-HO-1-L) was examined by immunohistochemistry, using a polyclonal antibody specific for total tau protein. Tg mice showed accumu- 
A

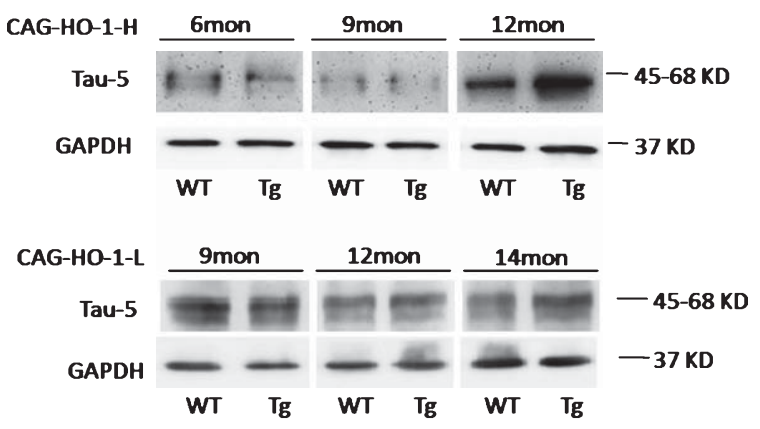

B

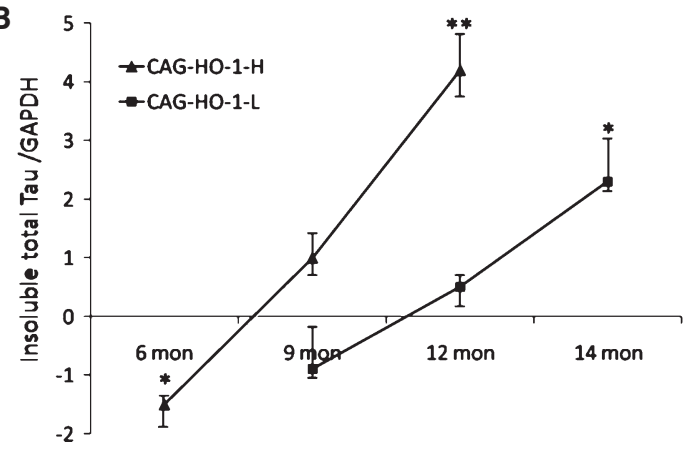

Fig. 4. Insoluble tau in the hippocampus and cerebral cortex of the mouse brain. A) Representative western blot image of total tau and GAPDH in WT and CAG-HO-1-H Tg mice at 6, 9, and 12 months old, respectively. B) Representative western blot image of total tau and GAPDH in WT and CAG-HO-1-L Tg mice at 9, 12, and 14 months old, respectively. C) Graph showing semi-quantitative analyses of insoluble total tau in Tg mice, with the value of WT mice set to 0 ; data represent relative values of $\mathrm{Tg}$ versus WT mice obtained from at least three replicates for each sample. ${ }^{*} p<0.05, * * p<0.01$.

lation of tau proteins in insoluble aggregates in large brain regions, with high expression in pyramidal neurons of the cerebral cortex and hippocampus (Fig. 2). Because tau protein plays a crucial role in maintaining the structure and function of microtubules, we examined the ultrastructure of microtubules by electron microscopy. The structure of the microtubules was severely destroyed, as demonstrated by the twining and dissolving of microtubules in the cerebral cortex of $\mathrm{Tg}$ mice (Fig. 3).

\section{Result 3. The effect of HO-1 overexpression on insoluble tau in mouse brain}

To further confirm the histological data, we examined the effects of Tg HO-1 on insoluble tau protein levels in the brains of HO-1 Tg mice. Insoluble tau was extracted from the hippocampus and cerebral cortex of both low and high expressing lines of mice at various ages. Total insoluble fractions were subjected to immunoblotting with a specific tau-5 antibody that recognizes all tau isoforms (Fig. 4A, B). Compared to WT littermates, the insoluble tau in Tg mice showed the same developmental tendency in both low and high expressing lines. First, the insoluble tau decreased in CAG-HO-1-H (6 mo) and CAG-HO-1-L (9 mo) Tg mice compared to WT mice. Second, the levels of insoluble tau in CAG-HO-1-H (9 mo) and CAG-HO1-L (12 mo) Tg mice rose until they were almost equal to the levels of tau expression in WT mice. Subsequently, the insoluble tau in CAG-HO-1-H (12 mo.) and CAG-HO-1-L (14 mo) Tg mice clearly increased relative to WT littermates (Fig. 4A, B). The effect of long term HO-1 overexpression on the formation of insoluble tau in brain is ultimately inhibited at earlier stages of disease, while it is induced in later disease states (Fig. 4 C).

\section{Result 4. Tg HO-1 affects phosphorylation of tau in Neuro2a cells}

As previously reported, phosphorylation is a key regulatory mechanism that disrupts the ability of tau to bind microtubules and promote their assembly [4]. As a result, we examined whether HO-1 would have any effect on the phosphorylation pattern of tau. We established two Neuro2a cell lines stably transfected with HO-1, expressing low levels of HO-1 (number 4) or high levels of HO-1 (number 1) (Fig. 5A). In $\mathrm{AD}$, tau is phosphorylated at multiple sites throughout its 441 amino acids, but some studies suggest that only specific phosphorylation sites, such as S396 or S202, are associated with neurodegeneration [16]. In this study, we chose to examine two phosphorylation sites of tau, Ser396 and Ser199/202. An siRNA assay using pLL3.7-shHO-1 was performed to verify the results in Neuro2a cell lines stably transfected with HO-1. The results showed that the phosphorylation state of p-tau (Ser396) and p-tau (Ser199/202) were significantly increased due to the overexpression of HO-1 (Fig. 5B). Transfection with pLL3.7-shHO-1 was able to effectively reverse this phenotype (Fig. 5D).

\section{Result 5. Tg HO-1 affects protein phosphorylation of tau in mouse brain}

We validated the effects of Tg HO-1 on the phosphorylation state of tau in mouse brain. Insoluble fractions from the hippocampus and cerebral cortex were extracted from mice of the same ages used in the 

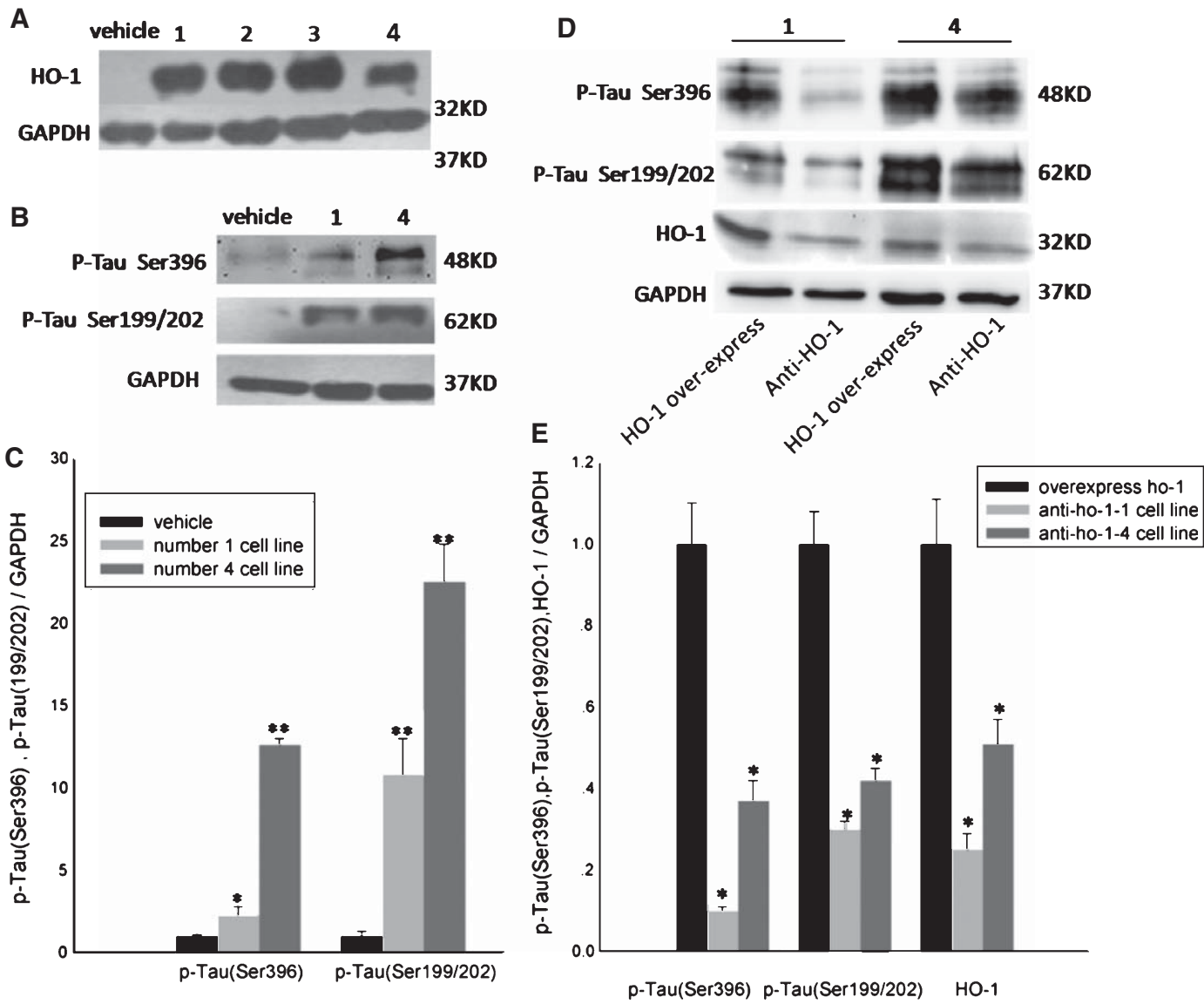

Fig. 5. Effect of HO-1 on the phosphorylation of tau in Neuro2a cells. A) Protein expression identification in Neuro2a cell lines stably transfected with HO-1. B) Western blot analysis demonstrated a significant increase in p-tau (Ser396) and p-tau (Ser199/202) following HO-1 overexpression. D) The pLL3.7-shHO-1 vector, which was used to inhibit the overexpression of HO-1, effectively reversed the phosphorylation state of p-tau (Ser396) and p-tau (Ser199/202) in Neuro2a cell lines stably transfected with HO-1. C, E) Graph showing semi-quantitative analyses of p-tau (Ser396), p-tau (Ser199/202) and HO-1, with control values set to 1; data represent Optical Density (O.D.) values obtained from at least three replicates for each sample. $* p<0.05, * * p<0.01$.

previous experiments. Specific antibodies against $\mathrm{p}$ tau (ser396) and p-tau (ser199/202) were used in immunoblotting (Fig. 6A-D). Compared to WT littermates, p-tau (ser396) and p-tau (ser199/202) of insoluble fractions from $\mathrm{Tg}$ mouse brains showed the same developmental tendency as insoluble total tau. Long term HO-1 overexpression has an induction effect on the formation of insoluble p-tau (ser396) and p-tau (ser199/202) in brain (Fig. 6E, F).

\section{Result 6. HO-1 overexpression may induce} the phosphorylation of tau by enhancing iron loading in mouse brain

Iron is one of the metabolites of HO-1. It was reported that iron-mediated oxidative stress, per- haps in association with cell signaling disturbances, could promote increased phosphorylation of the microtubule-associated protein tau [17]. We found that the non-heme iron content of the basal nucleus was significantly increased in 14-month-old CAG-HO-1 Tg mice compared to WT littermates (Fig. 7). Neuro2a cells were incubated with increasing concentrations of iron, ranging from 0 to $100 \mu \mathrm{M}$. Twenty micromoles per liter of Fe efficiently promoted the phosphorylation state of p-tau(Ser199/202) and p-tau(Ser396) (Fig. 8A, C). In Neuro2a cells stably transfected with HO-1, DFO was able to effectively reverse the induction of HO-1 phosphorylation of tau (Fig. 8B, D). These results suggest that HO-1 overexpression may induce the phosphorylation of tau by enhancing iron loading in the mouse brain. 


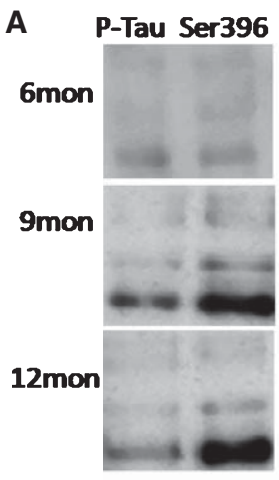

WT H

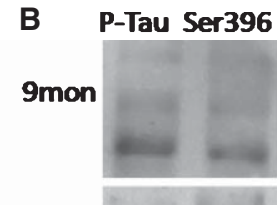

$12 \mathrm{mon}$

$14 \mathrm{mon}$

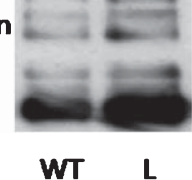

C

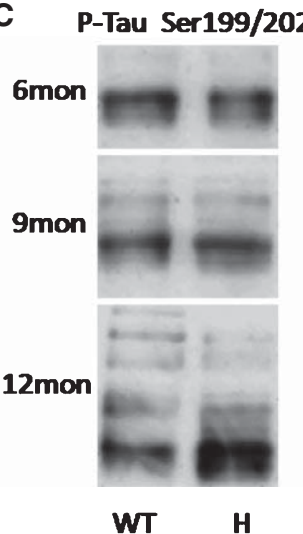

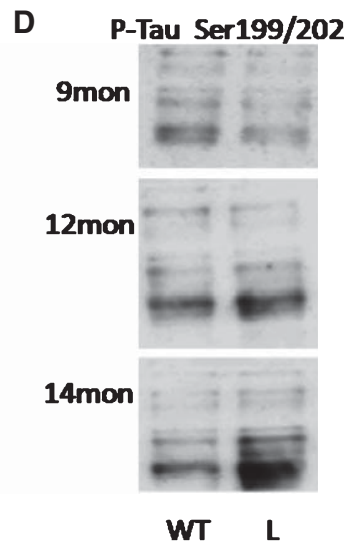

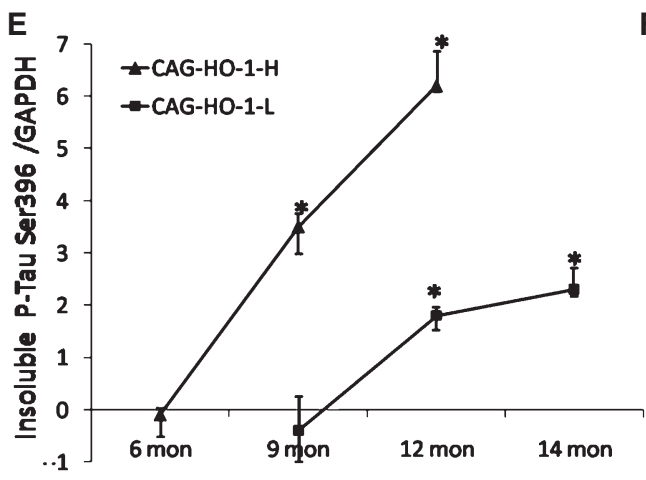

F

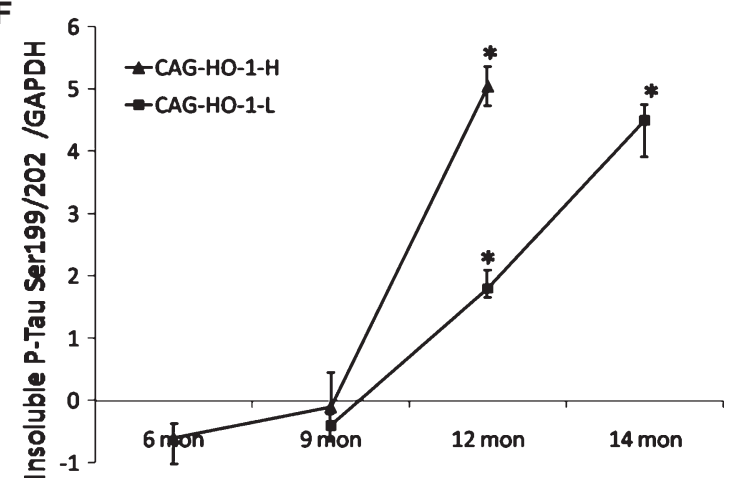

Fig. 6. The expression of insoluble p-tau in the hippocampus and cerebral cortex of mouse brain. A, B) Representative western blot images of p-tau (Ser396) in WT, CAG-HO-1-H, and CAG-HO-1-L Tg mice at different ages. C, D) Representative western blot images of p- tau (Ser199/202) in WT, CAG-HO-1-H, and CAG-HO-1-L Tg mice at different ages. E, F) Graph showing semi-quantitative analyses of insoluble p-tau (ser396) and p-tau (ser199/202), respectively, in Tg mice, with the value of WT mice set to 0; data represent relative values of Tg versus WT mice obtained from at least three replicates for each sample. $* p<0.05$.

\section{DISCUSSION}

We constructed a transgenic mouse that ubiquitously expresses mouse HO-1. The increased level of HO1 in transgenic mice is comparable to $\mathrm{AD}$ patients according to the report on the expression of HO-1 in the AD brain by Schipper HM [9]. At approximately 14 months old, transgenic mice present with a tauopathy phenotype. As shown with light microscopy, many nerve cells in the hippocampus and cerebral cortex from 14-month-old CAG-HO-1-L Tg mice were strongly immunoreactive for tau. These morphological findings were also found at the biochemical level. Insoluble tau protein in the hippocampus and cerebral cortex of 12-month-old CAG-HO-1-H and 14-monthold CAG-HO-1-L transgenic mice was found to be greatly increased using western blotting. Additionally, in Neuro2a cells stably expressing HO-1, we found that HO-1 can induce the phosphorylation of tau, using antibodies of against tau (ser199/202) and tau (ser396). Moreover, this induction could be reverted by DFO, an iron chelating agent. These observations in Neuro2a cells were confirmed in CAG-HO-1 $\mathrm{Tg}$ mice. In 12-month-old CAG-HO-1-H and 14-month-old CAG$\mathrm{HO}-1-\mathrm{L}$ transgenic mice, insoluble phosphorylated tau (ser199/202) and tau (ser396) was increased in the hippocampus and cerebral cortex, and the concentration of iron in the basal nucleus was elevated, compared to age-matched controls. These results suggest that long-term overexpression of HO-1 can promote phosphorylation and aggregation of insoluble tau; the effect of HO-1 on tau phosphorylation may have been mediated by producing excess iron.

Human neuropathological surveys have reported a correlation between HO-1 and tauopathy. However, the mechanism by which HO-1 leads to tauopathy was not determined. A few in vitro studies have investigated this question. At the cellular level, some studies 


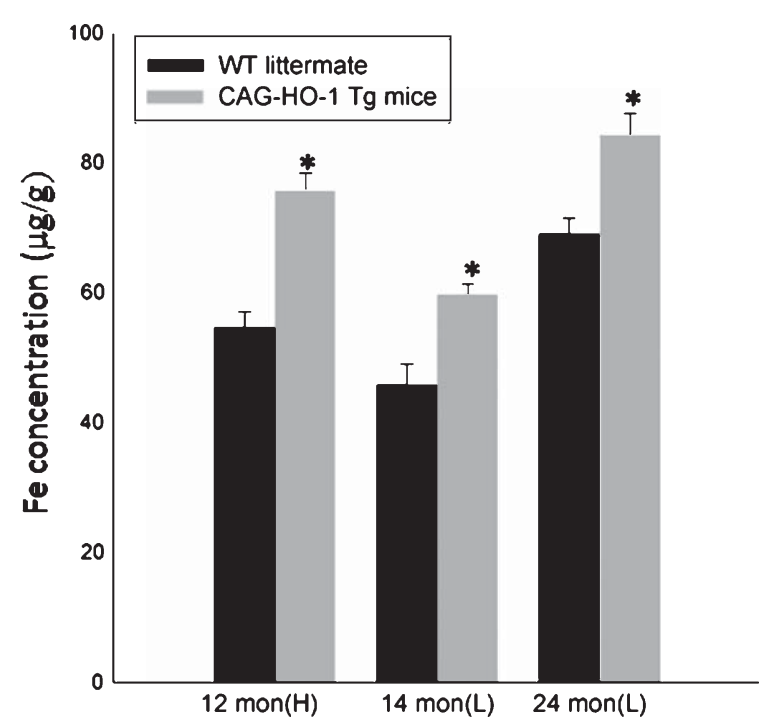

Fig. 7. HO-1 overexpression enhances iron loading in mouse brain. The basal nucleus of the brain was removed, and the concentration of iron was measured in a spectrophotometer. Non-heme iron content of the basal nucleus was significantly increased in CAG-HO-1 Tg mice, in 14- and 24-month-old CAG-HO-1-L mice and 12-monthold CAG-HO-1-H mice, compared to WT littermates. $* p<0.05$.

reported that HO-1 is able to inhibit tau expression [18] and trigger proteosome-mediated tau degradation [19]. However, the effect of long-term HO-1 overexpression in a whole organism may be different from its effect in cells. In this study, we demonstrated the relationship between HO-1 and tau aggregation in transgenic mice for the first time. Additionally, we found that HO-1 influenced tau phosphorylation at specific sites.

Among the features of the pathogenesis of $\mathrm{AD}$, iron deposition in the brain has become a focus of research in recent years. Many studies have shown that iron can induce aggregation of hyperphosphorylated tau [20]. Iron-mediated oxidative stress, perhaps in association with cell signaling disturbances, promotes phosphorylation of microtubule-associated protein tau and expression of cell cycle proteins in post-mitotic neurons [17, 21-23]. Iron might play a role in the aggregation of tau and lead to the formation of NFTs in the AD brain. However, the mechanism of brain iron deposition remains unclear. Overexpression of human HO-1 in cultured rat astroglia promotes trapping of non-transferrin-bound 55Fe by the mitochondrial compartment [24]. In this study, we showed for the first time that overexpression of HO-1 can increase the concentration of brain iron in vivo. This observation offers a potential pathway for iron deposition in the brain and provides an explanation for the tauopathy phenotype formed in CAG-HO-1 Tg mice.
In contrast to older CAG-HO-1 $\mathrm{Tg}$ mice, the insoluble total tau and insoluble phosphorylated tau (ser199/202) and tau (ser396) from the hippocampus and cerebral cortex in younger transgenic mice (6month-old CAG-HO-1-H and 9-month-old CAG-HO1-L) were less than that found WT mice. This suggests that the effect of $\mathrm{HO}-1$ overexpression on tau protein differs according to the length of HO-1 overexpression in vivo. At earlier stages, $\mathrm{HO}-1$ overexpression inhibits tau aggregation, which has a protective effect. However, in later stages, HO-1 overexpression begins to facilitate tau aggregation, which is harmful. Whether HO-1 up-regulation in the diseased nervous system plays a cytoprotective $[18,25]$ or neurodegenerative role $[24,26]$ is currently under debate. The different effects of HO-1 at distinct stages of pathogenesis in our study may account for the disparate data regarding the role of HO-1 induction in brain aging and disease. We suppose that the cumulative effect of HO-1 may come from its metabolites, leading to different results at different stages of disease in CAG-HO-1 Tg mice.

There is evidence indicating that the overexpression of HO-1 reduces the neurotoxin-induced cell death in transgenic mice and neuronal cultures, suggesting a cytoprotective role of HO-1. For example, HO-1 overexpression triggers proteosome-mediated protein degradation and prevents intracellular accumulation of abnormal protein aggregates and inclusions in human neuroblastoma M17 cells [19]. HO-1 may also be involved in neuroprotection in traumatic animal models $[27,28]$ and in excitotoxic brain damage and spinal cord injury [29]. It is possible that the protective role of HO-1 occurs by virtue of the anti-inflammatory and antioxidant capacities of $\mathrm{CO}$, biliverdin and bilirubin, a metabolite of biliverdin [30-36]. Up-regulation of HO-1 may provide cytoprotection by promoting the catabolism of the prooxidant heme to the radicalscavenging bile pigments, biliverdin and bilirubin. Bilirubin is an endogenous antioxidant that can remove oxygen radicals [35]. CO and bilirubin displayed antiapoptotic function in some studies [37, 38]. Additionally, intracellular iron is the principal regulator of ferritin synthesis. Iron released by HO-1 induces upregulation of ferritin synthesis, which protects the brain from oxidative damage [39]. In addition, some in vitro studies support our results in younger CAG-HO-1 Tg mice. In one study, Smith and colleagues [18] showed that tau expression decreased in a neuroblastoma cell line transfected with human HO-1 cDNA. Perhaps, at an earlier stage, HO-1 overexpression inhibits tau aggregation and mainly plays a protective role. 
A

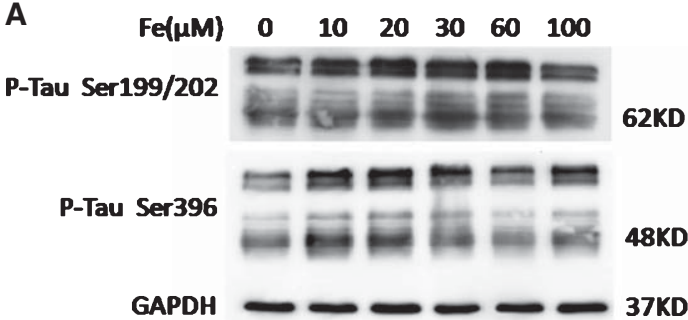

C

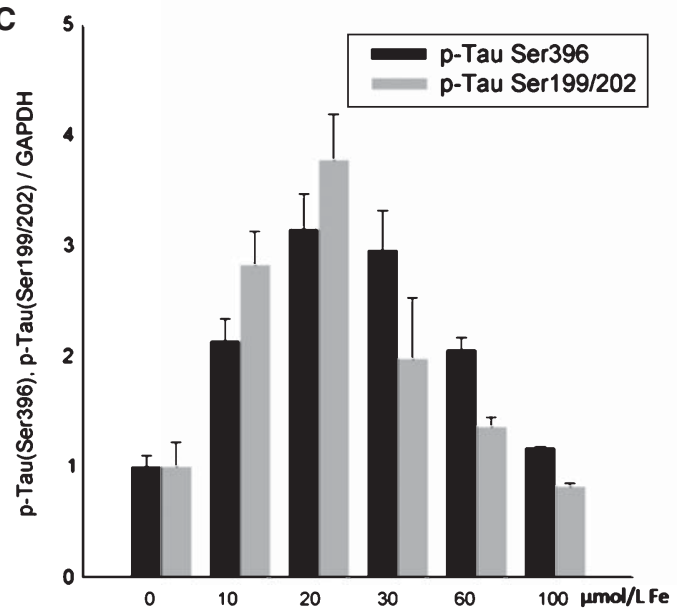

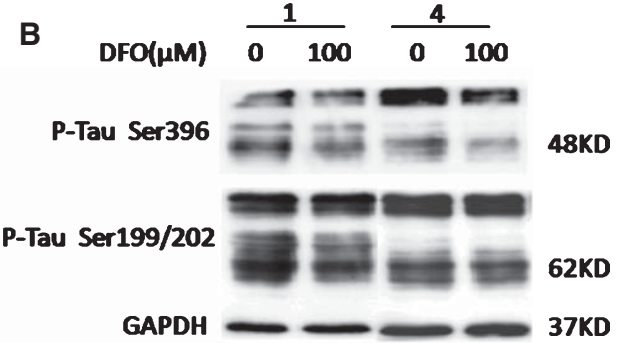

D

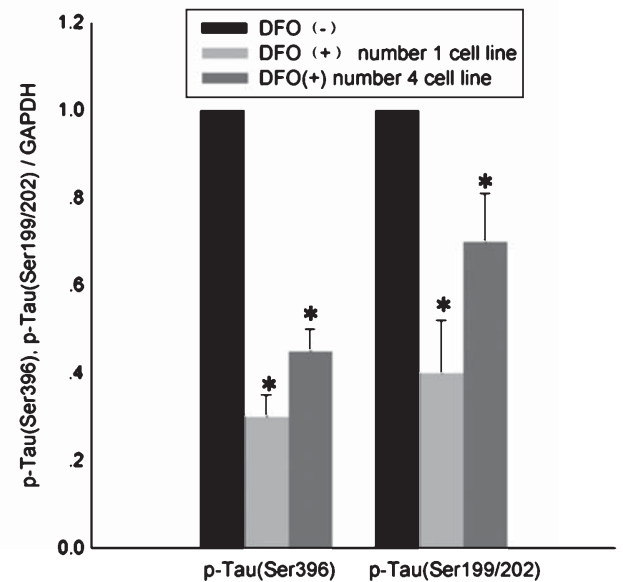

Fig. 8. HO-1 induces the phosphorylation of tau mediated by iron. A) Neuro2a cells were incubated with increasing concentrations of iron at 0 , $10,20,30,60$, and $100 \mu \mathrm{M}$. Cells were homogenized and subjected to western blot assays using antibodies against p-tau (Ser199/202) and p-tau (Ser396). C) $20 \mu \mathrm{mol} / \mathrm{L}$ Fe efficiently promoted the phosphorylation state of p-tau (Ser199/202) and p-tau (Ser396). B) DFO (100 $\mu$ M) was added to Neuro2a cell lines stably transfected with HO-1. Cells were homogenized and subjected to western blot assays. D) DFO effectively reverted the effect of HO-1 induction on phosphorylation of tau in Neuro2a cell lines stably transfected with HO-1. The graph shows semi-quantitative analyses of p-tau (Ser396) and p-tau (Ser199/202) with control values set to 1; data represent Optical Density (O.D.) values obtained from at least three replicates for each sample. * $p<0.05$.

In contrast, there is evidence indicating that the overexpression of HO-1 plays a detrimental role. For example, astroglia cells overexpressing HO-1 predispose co-cultured PC12 cells to oxidative injury [40]. Moreover, dynamic SIMS revealed intense foci of elemental iron within HMOX1-transfected cells, which co-localized with organelles identified as pathological mitochondria on the basis of size, shape, number, investing membranes, perinuclear deployment, and oxygen-labeling. These cytopathological changes indicate that $\mathrm{HO}-1$ overexpression in astrocytes promotes the classical ultrastructural features of macroautophagy, a process that has been demonstrated in the senescent and AD human brains [41]. It is possible that long-term overexpression of HO-1 might cause overproduction of metabolites. When the accumulation of metabolic products exceeds a certain threshold, these metabolites may show a toxic effect. For example, although experimental and epidemiological evidence suggests that bilirubin may serve as a physiological antioxidant [42, 43], abnormal accumulation of bilirubin may cause neurotoxicity [44]. Under certain circumstances, heme-derived iron and CO may exacerbate oxidative substrate damage by facilitating the production of reactive oxygen species within the mitochondria and other subcellular compartments [45-47]. In addition, "the iron hypothesis" deserves special attention as it is tightly linked to aging and various neurodegenerative diseases [46-48]. There is increasing evidence that iron is involved in the mechanisms that underlie many neurodegenerative diseases. High concentrations of reactive iron can increase oxidativestress via the Fenton reaction, inducing neuronal vulnerability, and iron accumulation might increase the toxicity of environmental or endogenous toxins, causing diseases like AD and PD [48]. Furthermore, in this study, we found long-term overexpression of HO- 1 increased the brain iron concentrations in the 
basal nucleus of CAG-HO-1 Tg mice. Therefore, in later stages, HO-1 may exacerbate neuropathology by long-term overexpression.

These data suggest a central role of long-term HO- 1 overexpression in the pathogenesis of AD. However, we have not discussed whether long-term HO-1 overexpression occurs in the pathogenesis of $\mathrm{AD}$ in humans. The free radical hypothesis of AD could provide a reasonable explanation for promoting HO-1 overexpression in AD. The free radical hypothesis of $\mathrm{AD}$ posits that the age-related accumulation of free radicals and reactive oxygen species damage the major components of cells, including the nucleus, mitochondrial DNA, membranes, and cytoplasmic protein, which results in oxidative stress. Oxidative stress, as an early event, is involved in the pathogenesis of most neurodegenerative disorders, including AD [49-51]. At early stages, HO-1, which is a very sensitive marker of oxidative stress, would be induced by the free radicals and oxidative stress produced by aging and would display protective functions against oxidation, inflammation and apoptosis. Age-related oxidative stress has been amply documented in $\mathrm{AD}$-affected brain tissues and may be responsible for induction of HO-1 in patients with $\mathrm{AD}$ [9]. As a result, HO-1 might be continually activated, resulting in long-term overexpression. Numbers of HO-1-immunoreactive neuroglia progressively increase in human cortical and subcortical brain regions with advancing age [52]. Thus, long-term HO-1 overexpression is likely to occur during aging and inflammation and following pro-oxidant stimuli (heme, Th1 cytokines, $\mathrm{A} \beta, \mathrm{H}_{2} \mathrm{O}_{2}$, dopamine, hyperoxia, UV light, heavy metals, prostaglandins, nitric oxide [53-55]), which are involved in AD and promote the generation and development of AD.

Circulating HO-1/HOS has served as a biomarker for the diagnosis of mild cognitive impairment and $\mathrm{AD}$ [56]. Of the 15 proteins found to be significantly altered in sera from patients with mild AD compared to normal patients or patients with of mild cognitive impairment, 14 contained HO-1, biliverdin reductase A or biliverdin reductase $\mathrm{B}$. This strongly implicates HO-1 as a potential biomarker for AD [57].

Pharmacological modulation of HO-1 levels in the brain, within therapeutic limits, shows promising results in models of AD, Parkinson's disease and other infectious diseases, such as malaria [39]. A more complete understanding of how HO-1 is involved in the pathogenesis of neurological diseases will be essential to develop therapeutic approaches to treat these diseases. In the following years, we will witness the description of chemicals, drugs and/or dietary products that cross the blood brain barrier efficiently, modulate $\mathrm{HO}-1$ expression and achieve neuroprotective and anti-inflammatory effects in vivo [39].

\section{ACKNOWLEDGMENTS}

This work was supported in part by Natural Science Foundation of Heilongjiang Province (QC2009C09), Education Department Foundation Heilongjiang Province (11531164), and National Natural Science Foundation of China (30971059).

Authors' disclosures available online (http://www.jalz.com/disclosures/view.php?id=845).

\section{REFERENCES}

[1] Querfurth HW, LaFerla FM (2010) Alzheimer's disease. $N$ Engl J Med 362, 329-344.

[2] Goedert M, Klug A, Crowther R (2006) Tau protein, the paired helical filament and Alzheimer's disease. J Alzheimers Dis 9 , 195-207.

[3] Maccioni RB, Farías G, Morales I, Navarrete L (2010) The revitalized tau hypothesis on Alzheimer's disease. Arch Med Res 41, 226-231.

[4] Stoothoff WH, Johnson GV (2005) Tau phosphorylation: physiological and pathological consequences. Biochim Biophys Acta 1739, 280-297.

[5] Ryter SW, Tyrrell RM (2000) The heme synthesis and degradation pathways: role in oxidant sensitivity. Heme oxygenase has both pro- and antioxidant properties. Free Radic Biol Med 28, 289-309.

[6] Vincent SR, Das S, Maines MD (1994) Brain heme oxygenase isoenzymes and nitric oxide synthase are co-localized in select neurons. Neuroscience 63, 223-231.

[7] Ham D, Schipper HM (2000) Heme oxygenase-1 induction and mitochondrial iron sequestration in astroglia exposed to amyloid peptides. Cell Mol Biol (Noisy-le-grand) 46, 587596.

[8] Butterfield DA, Griffin S, Munch G, Pasinetti GM (2002) Amyloid beta-peptide and amyloid pathology are central to the oxidative stress and inflammatory cascades under which Alzheimer's disease brain exists. JAlzheimers Dis 4, 193-201.

[9] Schipper HM, Cissé S, Stopa EG (1995) Expression of heme oxygenase-1 in the senescent and Alzheimer-diseased brain. Ann Neurol 37, 758-768.

[10] Schipper HM, Bennett DA, Liberman A, Bienias JL, Schneider JA, Kelly J, Arvanitakis Z (2006) Glial heme oxygenase-1 expression in Alzheimer disease and mild cognitive impairment. Neurobiol Aging 27, 252-261.

[11] Smith MA, Kutty RK, Richey PL, Yan SD, Stern D, Chader GJ, Wiggert B, Petersen RB, Perry G (1994) Heme oxygenase- 1 is associated with the neurofibrillary pathology of Alzheimer's disease. Am J Pathol 145, 42-47.

[12] Schipper HM (2011) Heme oxygenase-1 in Alzheimer disease: a tribute to Moussa Youdim. J Neural Transm 118, 381-387.

[13] Hogan B, Constanlini F, Lancy E (1986) Manipulating the Mouse Embryo. Cold Spring Harbor. NY, 332 pp.

[14] Kawahara K, Hashimoto M, Bar-On P, Ho GJ, Crews L, Mizuno H, Rockenstein E, Imam SZ, Masliah E(2008) Alpha- 
Synuclein aggregates interfere with Parkin solubility and distribution: role in the pathogenesis of Parkinson disease. J Biol Chem 283, 6979-6987.

[15] Foy AL, Williams HL, Cortell S, Conrad ME (1967) A modified procedure for the determination of nonheme iron in tissue. Anal Biochem 18, 559-563.

[16] Augustinack JC, Schneider A, Mandelkow EM, Hyman BT (2002) Specific tau phosphorylation sites correlate with severity of neuronal cytopathology in Alzheimer's disease. Acta Neuropathol 103, 26-35.

[17] Egana JT, Zambrano C, Nunez MT, Gonzalez-Billault C, Maccioni RB (2003) Iron-induced oxidative stress modify tau phosphorylation patterns in hippocampal cell cultures. Biometals 16, 215-223.

[18] Takeda A, Perry G, Abraham NG, Dwyer BE, Kutty RK, Laitinen JT, Petersen RB, Smith MA (2000) Overexpression of heme oxygenase in neuronal cells, the possible interaction with Tau. J Biol Chem 275, 5395-5399.

[19] Song W, Patel A, Qureshi HY, Han D, Schipper HM, Paudel HK (2009) The Parkinson disease-associated A30 P mutation stabilizes alpha-synuclein against proteasomal degradation triggered by heme oxygenase-1 over-expression in human neuroblastoma cells. J Neurochem 110, 719-733.

[20] Yamamoto A, Shin RW, Hasegawa K, Naiki H, Sato H, Yoshimasu F, Kitamoto T (2002) Iron (III) induces aggregation of hyperphosphorylated tau and its reduction to iron (II) reverses the aggregation: implications in the formation of neurofibrillary tangles of Alzheimer's disease. J Neurochem 82, 1137-1147.

[21] Zhu X, Rottkamp CA, Boux H, Takeda A, Perry G, Smith MA (2000) Activation of p38 kinase links tau phosphorylation, oxidative stress, and cell cycle-related events in Alzheimer disease. J Neuropath Exp Neurol 59, 880-888.

[22] Zhu X, Raina AK, Lee H, Casadesus G, Smith MA, Perry $\mathrm{G}$ (2004) Oxidative stress signaling in Alzheimer's disease. Brain Res 1000, 32-39.

[23] Kondziella D, Zetterberg H (2008) Hyperphosphorylation of tau protein in superficial CNS siderosis. J Neurol Sci 273, 130-132.

[24] Schipper HM (1999) Glial HO-1 expression, iron deposition and oxidative stress in neurodegenerative diseases. Neurotox Res 1, 57-70.

[25] Dwyer BE, Nishimura RN, Lu SY (1995) Differential expression of heme oxygenase- 1 in cultured cortical neurons and astrocytes determined by the aid of a new heme oxygenase antibody. Response to oxidative stress. Brain Res Mol Brain Res 30, 37-47.

[26] Panizzon KL, Dwyer BE, Nishimura RN, Wallis RA (1996) Neuroprotection against CA1 injury with metalloporphyrins. Neuroreport 7, 662-666.

[27] Fukuda K, Richmon JD, Sato M, Sharp FR, Panter SS, Noble LJ (1996) Induction of heme oxygenase-1 (HO-1) in glia after traumatic brain injury. Brain Res 736, 68-75.

[28] Beschorner R, Adjodah D, Schwab JM, Mittelbronn M, Pedal I, Mattern R, Schluesener HJ, Meyermann R (2000) Long-term expression of heme oxygenase-1 (HO-1, HSP-32) following focal cerebral infarctions and traumatic brain injury in humans. Acta Neuropathol 100, 377-384.

[29] Ahmad AS, Ahmad M, de Brum-Fernandes AJ, Doré S (2005) Prostaglandin EP4 receptor agonist protects against acute neurotoxicity. Brain Res 1066, 71-77.

[30] Stocker R, Yamamoto Y, Mc Donagh AF, Glazer AN, Ames BN (1987) Bilirubin is an antioxidant of possible physiological importance. Science 235, 1043-1046.
[31] Nakagami T, Toyomura K, Kinoshita T, Morisawa S (1993) A beneficial role of bile pigments as an endogenous tissue protector: anti-complement effects of biliverdin and conjugated bilirubin. Biochim Biophys Acta 1158, 189-193.

[32] Llesuy SF, Tomaro ML (1994) Heme oxygenase and oxidative stress. Evidence of involvement of bilirubin as physiological protector against oxidative damage. Biochim Biophys Acta 1223, 9-14.

[33] Doré S, Sampei K, Goto S, Alkayed NJ, Guastella D, Blackshaw S, Gallagher M, Traystman RJ, Hurn PD, Koehler RC, Snyder SH (1999) Heme oxygenase-2 is neuroprotective in cerebral ischemia. Mol Med 5, 656-663.

[34] Barañano DE, Snyder SH (2001) Neural roles for heme oxygenase: contrasts to nitric oxide synthase. Proc Natl Acad Sci U S A 98, 10996-11002.

[35] Turkseven S, Kruger A, Mingone CJ, Kaminski P, Inaba M, Rodella LF, Ikehara S, Wolin MS, Abraham NG (2005) Antioxidant mechanism of heme oxygenase-1 involves an increase in superoxide dismutase and catalase in experimental diabetes. Am J Physiol Heart Cire Physiol 289, H701-H707.

[36] Kapturczak MH, Wasserfall C, Brusko T, CampbellThompson M, Ellis TM, Atkinson MA, Agarwal A (2004) Heme oxygenase-1 modulates early inflammatory responses evidence from the heme oxygenase-1 deficient mouse. Am J Pathol 165, 1045-1053.

[37] Wang X, Wang Y, Kim HP, Nakahira K, Ryter SW, Choi AM (2007) Carbon monoxide protects against hyperoxiainduced endothelial cell apoptosis by inhibiting reactive oxygen species formation. J Biol Chem 282, 1718-1726.

[38] Brouard S, Berbera P, Tobiasche E, Seldon MP, Bach FH, Soares MP (2002) Heme oxygenase-1-derived carbon monoxide requires the activation of transcription factor NF- $\kappa$ B to protect endothlial cells from tumor necrisis factor- $\alpha$-mediated apoptosis. J Biol Chem 277, 17950-17961.

[39] Cuadrado A, Rojo AI (2008) Heme oxygenase-1 as a therapeutic target in neurodegenerative diseases and brain infections. Curr Pharm Design 14, 429-442.

[40] Song L, Song W, Schipper HM (2007) Astroglia overexpressing heme oxygenase-1 predispose co-cultured PC12 cells to oxidative injury. J Neurosci Res 85, 2186-2195.

[41] Zukor H, Song W, Liberman A, Mui J, Vali H, Fillebeen C, Pantopoulos K, Wu TD, Guerquin-Kern JL, Schipper HM (2009) HO-1-mediated macroautophagy: a mechanism for unregulated iron deposition in aging and degenerating neural tissues. J Neurochem 109, 776-791.

[42] Baranano DE, Rao M, Ferris CD, Snyder SH (2002). Biliverdin reductase: a major physiologic cytoprotectant. Proc Natl Acad Sci U S A 99, 16093-16098.

[43] Liu Y, Li P, Lu J, Xiong W, Oger J, Tetzlaff W, Cynader M (2008) Bilirubin possesses powerful immunomodulatory activity and suppresses experimental autoimmune encephalomyelitis. J Immunol 181, 1887-1897.

[44] Cashore WJ (1990) The neurotoxicity of bilirubin. Clin Perinatol 17, 437-448.

[45] Desmard M, Boczkowski J, Poderoso J, Motterlini R (2007) Mitochondrial and cellular heme-dependent proteins as targets for the bioactive function of the heme oxygenase/carbon monoxide system. Antioxid Redox Signal 9, 21392155.

[46] Egaña JT, Zambrano C, Nuñez MT, Gonzalez-Billault C, Maccioni RB (2003) Iron-induced oxidative stress modify tau phosphorylation patterns in hippocampal cell cultures. Biometals 16, 215-223. 
[47] Ke Y, Ming Qian Z (2003) Iron misregulation in the brain: a primary cause of neurodegenerative disorders. Lancet Neurol 2, 246-253.

[48] Zecca L, Youdim MB, Riederer P, Connor JR, Crichton RR (2004) Iron, brain ageing and neurodegenerative disorders. Nat Rev Neurosci 5, 863-873.

[49] Hartman D (1995) Free radical theory of aging: Alzheimer's disease pathogenesis. AGE 18, 97-119.

[50] Halliwell B, Gutteridge JMC (1989) Free radicals in biology and medicine. Oxford, United Kingdom: Oxford University Press.

[51] Packer L, Prilipko L, Christen Y, (eds). (1992) Free radicals in the brain. Springer-Verlag, Heidelberg, Germany.

[52] Hirose W, Ikematsu K, Tsuda R (2003) Age-associated increases in heme oxygenase-1 and ferritin immunoreactivity in the autopsied brain. Leg Med (Tokyo) 5 Suppl 1, S360-S366.
[53] Dennery PA (2000) Regulation and role of heme oxygenase in oxidative injury. Curr Top Cell Regul 36, 181-199.

[54] Schipper HM (2000) Heme oxygenase-1: role in brain aging and neurodegeneration. Exp Gerontol 35, 821-830.

[55] Loboda A, Jazwa A, Grochot-Przeczek A, Rutkowski AJ, Cisowski J, Agarwal A, Jozkowicz A, Dulak J (2008) Heme oxygenase-1 and the vascular bed: from molecular mechanisms to therapeutic opportunities. Antioxid Redox Signal 10, 1767-1812.

[56] Schipper HM (2007) The role of biologic markers in the diagnosis of Alzheimer's disease. Alzheimers Dement 3, 325-332.

[57] Mueller C, Zhou W, Vanmeter A, Heiby M, Magaki S, Ross MM, Espina V, Schrag M, Dickson C, Liotta LA, Kirsch WM (2010) The heme degradation pathway is a promising serum biomarker source for the early detection of Alzheimer's disease. J Alzheimers Dis 19, 1081-1091. 